\title{
RADIOCHEMICAL SEPARATION OF INDIUM BY AMALGAM-EXCHANGE
}

\author{
R. R. RUCH*, J. R. DeVoe† and W. W. MeINKe \\ Department of Chemistry, University of Michigan, Ann Arbor, Michigan, U.S.A.
}

(Received 18 July 1961. Accepted 10 August 1961)

\begin{abstract}
Summary-The radiochemical separation of indium by an amalgam-exchange technique has been critically evaluated for the aqueous hydrogen bromide system. The efficiency and contamination of the separation has been studied using tracers of 19 different representative elements. Yields of contaminating elements are reduced in most cases to less than $0.1 \%$, and indium yields are usually above $95 \%$. The procedure requires no special equipment, and takes about $11 \mathrm{~min}$ overall. A number of factors affecting the separation have been studied and improved.
\end{abstract}

THE principle of isotopic exchange between a metal ion and an amalgam of the metal has been applied to cadmium ${ }^{1,3}$ and zinc $^{5}$ with considerable success. Preliminary work ${ }^{1}$ also indicated that indium could be readily adapted to this type of separation. Sunderman and others ${ }^{6,8}$ have given extensive yield and concentration data on a number of radiochemical separations of indium which can form a solid basis for a general evaluation of this amalgam-exchange method versus standard separation techniques.

A procedure has been developed for the aqueous hydrogen bromide system, which gives high yields of indium with good decontamination. Many factors which affect the procedure, such as concentrations of reagents, interferences, time of agitation, etc., have been studied and evaluated.

The total separation procedure involves two isotopic exchange steps. In the first exchange, radioactive indium selectively exchanges with inactive indium in the mercury phase:

$$
\mathrm{In}(\mathrm{Hg})+\mathrm{In}^{* 3+} \rightleftarrows \mathrm{In} *(\mathrm{Hg})+\mathrm{In}^{3+}
$$

The requirement here is that the concentration of indium in the amalgam should be much greater than the concentration of indium in the aqueous phase. The mercury phase is then removed, and the radioactive indium is back-exchanged into the aqueous phase by contact with higher concentrations of indium ion. Cobalt ${ }^{\mathrm{II}}$ ion was also used for a few experiments in this back-exchange process.

\section{Apparatus}

\section{EXPERIMENTAL}

The separations are made in a 1/2-oz Boston-round bottle with polyethylene insert screw cap (available from Plax Corp., Bloomfield, Conn.). This is clamped in a mechanical shaker (Burrell Wrist-Action Shaker, Model 33) manufactured by the Burrcll Corporation, Pittsburgh, Pa., to which an extension arm of 12 inches has been connected to give added radial action.

All radioactivity measurements were made with a Nuclear-Chicago Model DS-3 scintillation well counter as described previously. ${ }^{2,6}$

* Present address: General Atomics, San Diego 12, California, U.S.A.

$\dagger$ Present address: National Bureau of Standards, Washington 25, D.C., U.S.A. 


\section{Reagents}

Amalgams: These were prepared by adding (under water purged with nitrogen) the appropriate weight of indium foil to $10 \mathrm{~g}$ of reagent-grade mercury which had been further purified by shaking with dilute nitric acid and rinsing 3 to 4 times with distilled water. The indium foil had also been subjected to dilute nitric acid and distilled water rinses before weighing.

Cobalt eluent solution: $100 \mathrm{mg}$ of cobalt (as cobalt chloride) per $\mathrm{ml}$ in $0.4 \mathrm{~N}$ hydrochloric acid.

Indium eluent solution: $10 \mathrm{mg}$ of indium (as indium nitrate) per $\mathrm{ml}$ in $0.4 \mathrm{~N}$ nitric acid.

Indium metal foil: $99.9 \%$ pure, Indium Corporation of America, Utica, New York.

Mercury: Baker and Adamson, triple distilled, analytical reagent.

Nitrogen gas: water-pumped, $99.99 \%$ pure, Liquid Carbonic Co.

All other non-radioactive reagents were of C.P. or analysed reagent grade.

All tracers used in this work have been described previously (Table $\mathrm{II}^{2}$ and Table $\mathbf{I}^{2}$ ).

\section{Amalgam-exchange procedure}

Place $2 \mathrm{ml}$ of $0.1 \mathrm{M}$ hydrobromic acid solution, containing tracers of contaminating ions $\left(10^{5}\right.$ to $10^{6}$ cpm) plus microgram amounts of inactive indium in a bottle. Chemical contamination added by the aliquots of contaminating tracers is negligible. Radioactive indium and non-radioactive interferences are used for yield determinations. Mix well. Add $0.5 \mathrm{ml}$ of mercury as scavenger, cap the bottle, and shake for $1 \mathrm{~min}$. Remove the mercury layer. Purge the system (both liquid and air above it in bottle) with nitrogen gas for $1 \mathrm{~min}$. Add $75 \mu \mathrm{l}(\sim 1.0 \mathrm{~g})$ of indium amalgam containing $0.2 \%$ of indium by weight ( $\sim 2 \mathrm{mg}$ ). Quickly cap the bottle and shake mechanically for $4 \mathrm{~min}$.

Decant the aqueous layer, transfer the amalgam to a new bottle, and wash twice with 2-ml portions of distilled water. Transfer the amalgam to a new bottle containing $2 \mathrm{ml}$ of indium eluent solution. Add $0.5 \mathrm{ml}$ of mercury to dilute the amalgam, cap the bottle, and shake mechanically for $5 \mathrm{~min}$. Take a $100-\mu \mathrm{l}$ aliquot of supernate for counting. The total time for separation is about $11 \mathrm{~min}$.

\section{Cobalt ${ }^{\mathrm{II}}$ ion back-exchange procedure}

Decontamination studies were also made employing cobalt ${ }^{\mathrm{II}}$ ions as the eluent instead of indium. The procedure is the same as above except that a $2 \%$ (instead of $0.2 \%$ ) indium amalgam was used and a 2 -ml portion of the cobalt eluent solution was substituted in the final step for the indium eluent.

\section{DISCUSSION AND RESULTS}

A number of preliminary experiments were made to determine the optimum procedure to use for yield and contamination studies. Several solvent systems in addition to hydrobromic acid were investigated. For typical conditions $0 \cdot 1 \mathrm{M}$ systems of $\mathrm{HF}, \mathrm{HCl}, \mathrm{HBr}$, and $\mathrm{HI}$ gave yields of about $3 \%, 91 \%, 98 \%$, and $97 \%$ respectively. The last two appear to give similarly high readings but the presence of free iodine in the $\mathrm{HI}$ system, as evidenced by discolouration, could lead to complications because of its oxidising character. Therefore hydrobromic acid was used.

Similar studies with different concentrations of $\mathrm{HBr}$ gave yields of $98 \%, 98 \%$, and $79 \%$ for procedures using $0.5 M, 0.1 M$, and $0.01 M \mathrm{HBr}$ respectively. Higher concentrations of acid generally tend to decrease the yield, and thus $0 \cdot 1 M \mathrm{HBr}$ was used for the standard procedure.*

Failure to purge the system with nitrogen leads to a noticeable decrease in yield. For a $0.2 \%$ indium amalgam, however, only a fraction of a minute is required to rid the system of this oxygen effect. If no purging with nitrogen is performed, there is sufficient oxygen trapped in the bottle above the solution to oxidise indium from the amalgam into the aqueous phase on vigorous agitation, and thus to decrease the capacity of the amalgam for overall isotopic exchange.

* The results of these and other specific runs will be included in our AEC Progress Report No. 10, November, 1961 , edited by R. S. Maddock and W. W. Meinke. 
In the amalgam-exchange procedure, the separation of the radioisotope takes place by virtue of the rapid exchange which is known to occur between an element in the form of a dilute amalgam and its ions in solution. If there are many more inactive atoms of the element in the amalgam than there are of its radioisotope in solution, the amalgam exchange will result in most of the activity being incorporated into the amalgam.

Since the conditions used for these separations are far from ideal, experiments using different amounts of indium in the amalgam and in the aqueous layer indicate the limiting practical conditions which should be applied to this separation. Procedures using a $2 \%$ amalgam gave yields of $94-96 \%$ for concentrations of $0.4-50 \mu \mathrm{g}$ of indium per $\mathrm{ml}$ in the aqueous solution. A slight reduction in yield to $90 \%$ was observed when this aqueous concentration was increased to $500 \mu \mathrm{g} / \mathrm{ml}$.

With an aqueous concentration of $\sim 2 \mu \mathrm{g}$ of indium per ml, yields of about $97 \%$, $96 \%, 90 \%, 44 \%$, and $1 \%$ were obtained for amalgams containing $2 \%, 0.2 \%, 0.02 \%$, $0.002 \%$, and $0.0002 \%$ of indium, respectively. Since the results with $2 \%$ and $0.2 \%$ amalgams are about equally good, both have been used in some of the experiments.

Problems of air oxidation of the amalgam and of oxidation by microgram concentrations of the contaminants combine to reduce the yields at lower amalgam concentrations, so that it was felt that no smaller than $0.2 \%$ amalgam should be used for a general procedure.

Yields also depend upon the duration and type of agitation employed for the initial extraction and for the back-extraction. With the equipment mentioned above, yields increased regularly with time of shaking and levelled out after $3-4 \mathrm{~min}$ of agitation. In the back-extraction process there was a sharp rise until about $3 \mathrm{~min}$ with a gradual continuation of the rise after this time. Thus, the conditions chosen as optimum were a 4-min agitation for the initial extraction and a 5-min agitation for the back-extraction.

Methods other than shaking might be used to produce an intimate contact between the amalgam and the solution and thus to speed up this approach to equilibrium. Some preliminary studies have been made using an ultrasonic generator to disperse the drop of amalgam in the aqueous phase, but this method was so violent that it left some of the amalgam in suspension, and subsequent centrifuging was required to clear the solution.

The resultant optimum procedure has been outlined above. The degree of separation of indium obtained with this procedure from a number of elements representative of the periodic table is shown in Table I. For many of the elements the decontamination afforded was greater than could be measured with the levels of tracer used. It should be kept in mind, however, that these high decontamination values are in any case meant to give only a general indication of results, since at these levels, amounts of contaminants carricd along are very dependent upon the techniques of manipulation.

These results are also plotted in Fig. 1 along with comparative values for decontamination by other methods such as bromide extraction, ion-exchange, and sulphide precipitation. ${ }^{6}$ In general, the amalgam-exchange procedure gives somewhat better decontamination than the bromide extraction and considerably better than the other two methods. In addition, it is more convenient and less messy than the bromide extraction.

Some yield and decontamination values were also determined by the cobalt 
TABle I.-SEPARATION OF INDIUM AND CONTAMINANTS, AMALGAM EXCHANGE PROCEDURE ${ }^{\natural}$

\begin{tabular}{|c|c|c|c|}
\hline Tracer $^{b}$ & Weight, $\mu g^{c}$ & $\begin{array}{l}\text { Reduction potential, } \\
\text { volts } s^{\mathrm{d}}\end{array}$ & Separated, $\%$ \\
\hline${ }^{131} \mathbf{I}$ & C.F.; I- & e & $<0.01$ \\
\hline${ }^{137} \mathrm{Cs}$ & 1 & $-2 \cdot 92$ & $<0.01$ \\
\hline${ }^{90} \mathrm{Sr}-{ }^{90} \mathrm{Y}$ & C.F. & $-2 \cdot 89,-2 \cdot 37$ & $<0.01$ \\
\hline${ }^{144} \mathrm{Ce}-{ }_{-144}^{14} \mathrm{Pr}$ & C.F. & $-2.48,-2.47$ & $<0.01$ \\
\hline${ }^{85} \mathrm{Zr}^{-95} \mathrm{Nb}$ & C.F. & $-1.53,-1 \cdot 1$ & $<0.01$ \\
\hline${ }^{182} \mathrm{Ta}$ & 970 & -0.81 & $<0.01$ \\
\hline${ }^{65 \mathrm{Zn}}$ & 200 & -0.76 & $<0.01$ \\
\hline${ }^{51} \mathrm{Cr}$ & $2 \cdot 5$ & -0.74 & $<0.01$ \\
\hline${ }^{115 \mathrm{~m}} \mathrm{Cd}$ & 10 & -0.40 & 0.7 \\
\hline${ }^{204} \mathrm{Tl}$ & 420 & -0.34 & 30 \\
\hline${ }^{1.14 \pi n} \mathrm{In}$ & 3 & $-0 \cdot 34$ & $96 \cdot 6 \pm 0.5$ \\
\hline${ }^{80} \mathrm{Co}$ & 2 & -0.28 & $<0.01$ \\
\hline${ }^{118} \mathrm{Sn}$ & 270 & -0.14 & 28 \\
\hline${ }^{124} \mathrm{Sb}$ & $3.5\left(\mathrm{SbO}^{+}\right)$ & $+0 \cdot 21$ & 1 \\
\hline${ }^{106} \mathrm{Ru}-{ }^{106} \mathrm{Rh}$ & $6\left(\mathrm{RuCl}_{5}^{2-}\right)$ & $+0.60,+0.25$ & $0 \cdot 1$ \\
\hline${ }^{75} \mathrm{Se}$ & $11 \cdot 5\left(\mathrm{SeO}_{8}^{2-}\right)$ & +0.74 & $<0.01$ \\
\hline${ }^{192} \mathrm{Ir}$ & $1\left(\mathrm{IrCl}_{0}^{2-}\right)$ & +0.77 & $<0.01$ \\
\hline${ }^{203} \mathrm{Hg}$ & 140 & +0.79 & 1 \\
\hline${ }^{110} \mathrm{Ag}$ & 16 & +0.80 & 0.04 \\
\hline
\end{tabular}

a Average of duplicate runs except for indium, which is the average of five runs. Error is "standard deviation".

b Elements have been listed in order of their reduction potentials.

c Weight of inactive element present before separation. C.F. $=$ carrier free.

d Standard reduction potential of lowest stable oxidation state to the elemental state. Data taken from Latimer. $^{4}$

e Iodine is in its lowest reduced state.

eluent procedure. The indium and cobalt eluent systems appear to be comparable from the indium yield point of view but the indium eluent seems to give somewhat better decontamination for several of the elements.

The yield of the amalgam-exchange procedure can be affected by macro quantities of different reagents. The yield is quite insensitive to mineral acids, except for oxidising acids such as nitric acid in higher concentrations. Sulphates, phosphates, and alkaline materials decrease the yield considerably, as do oxidising agents in general. The fact that $\mathrm{HBr}$ is present in $0 \cdot 1 M$ amounts during the exchange procedure appears to "buffer out" some of the possible difficulties with certain reagents. For example, when $\mathrm{HF}$ is used alone at $0.1 \mathrm{M}$ concentration, a yield of only a few per cent is obtained whereas in the presence of $0.1 M \mathrm{HBr}$ the yield is above $90 \%$. Some of these interference studies are summarised in Table II where the molarity of typical reagents is listed opposite the concentration near which the yield of indium appeared to drop below $85 \%$.

Interferences from foreign cations appear to be small except where their reduction potential is such that they might be reduced by the amalgam or form precipitates with. the reagents. When a cation is also an oxidising agent, additional problems are encountered and reduction to its lowest state by a reagent such as chromium ${ }^{I I}$ sulphate is necessary before the exchange step should be attempted. ${ }^{3}$

The yield of selenium in Table $\mathrm{I}$ is surprisingly low in contrast to the $17 \%$ yields found in a study of the cadmium amalgam exchange procedure. ${ }^{3}$ This discrepancy 


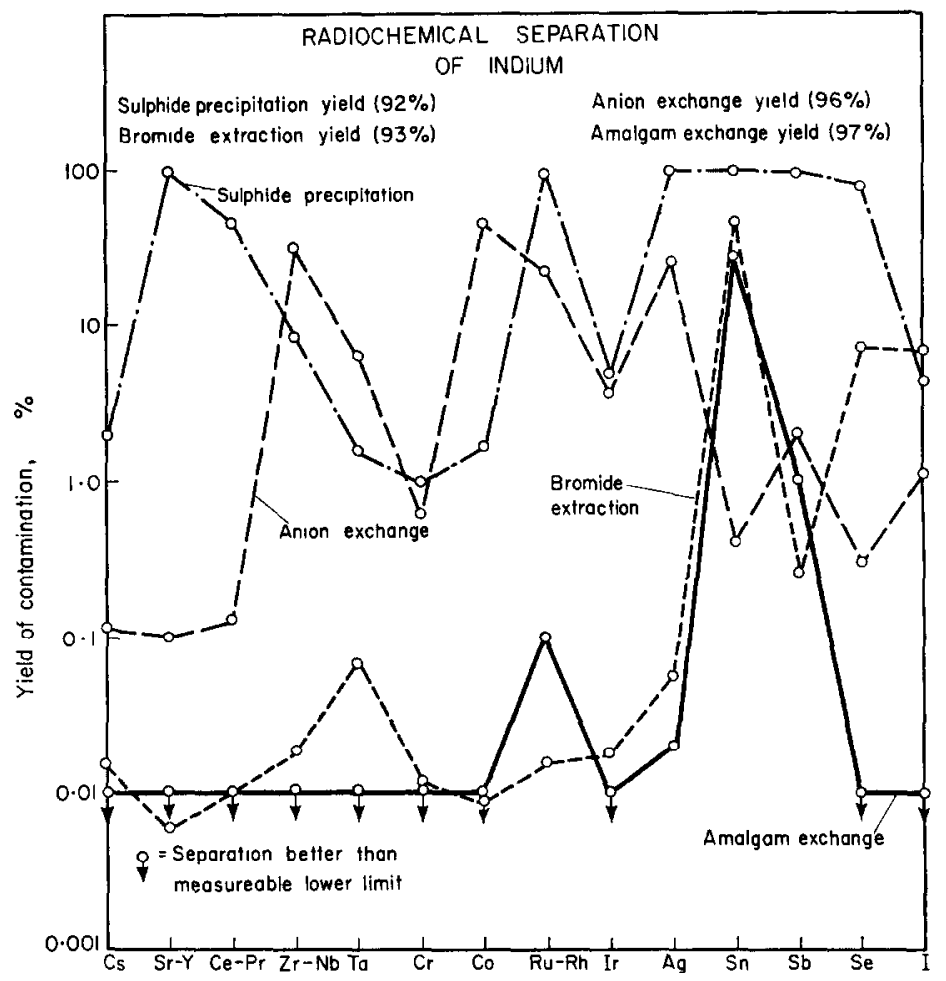

Fig. 1.-Experimental contamination for four types of indium separations.

is apparently caused by a difference in manipulation. In this indium work, the amalgam drop was brought into contact with an absorbent tissue to remove excess water after washing and before the back-extraction. At this point, the selenium, which upon reduction had formed a thin film on the surface of the mercury, mechanically rubs off on the tissue.

TABLE II,-INTERFERFNCE SUMMARY, AMALGAM EXCHANGE PROCEDURE

(All taken in presence of $0.1 M \mathrm{HBr}$ )

\begin{tabular}{l|c}
\hline \multicolumn{1}{c|}{ Species } & $\begin{array}{c}\text { Molarity at which indium } \\
\text { yield reduces below 85\% }\end{array}$ \\
\hline $\mathrm{HF}$ & 2.5 \\
$\mathrm{HCl}$ & 10 \\
$\mathrm{HI}$ & 2 \\
$\mathrm{HClO}$ & 6 \\
$\mathrm{HNO}_{3}$ & 1.0 \\
$\mathrm{H}_{3} \mathrm{PO}_{4}$ & 0.5 \\
$\mathrm{H}_{2} \mathrm{SO}_{4}$ & 0.4 \\
$\mathrm{Na}_{2} \mathrm{SO}_{4}$ & 0.25 \\
$\mathrm{NH}_{4} \mathrm{NO}_{3}$ & 1.0 \\
$\mathrm{NaClO}_{4}$ & 0.25 \\
$\mathrm{Citric} \mathrm{Acid}_{\text {Sodium tartrate }}$ & 0.5 \\
Sodium acetate & 0.05 \\
\hline
\end{tabular}


The amalgam-exchange procedure for the separation of radioisotopes of indium is rapid and selective. It yields high decontamination from most elements and is relatively insensitive to interferences except for oxidising agents. It is somewhat better than the best previous radiochemical separation (bromide extraction) for this element and is more convenient to use since it avoids the nccessity of working with inflammable ethers, and since the separation of phases is much more simple because of their high immiscibility.

Acknowledgement-This work was supported in part by the U.S. Atomic Energy Commission.

Zusammenfassung-Die radiochemische Abtrennung von Indium durch eine Methode mittels Amalgamaustausches wurde für das System Wasserstof-Bromid (in wasser) untersucht. Wirkungsgrad und Verunreinigungen der Trennung wurden studiert, wobei Tracer von 19 verschiedenen Elementen, verwendet wurden. Die Menge der Verunreinigung für die meisten Elemente wird auf 0.1\% reduziert während die Ausbeute an Indium für gewöhnlich über $90 \%$ bleibt. Die Methode benötigt keine besonderen Ausrüstungsgegenstände und der Zeitbedarf ist ungefähr $11 \mathrm{~min}$. Eine Anzahl von Faktoren, welche die Trennung beeinflussen wurde studiert und die optimalen Bedingungen erarbeitet.

Résumé - La séparation radiochimique de l'indium par une technique d'échange sur amalgame a été examinée de façon critique pour le système aqueux hydrogène-bromure. L'efficacité et la contamination de la séparation ont été étudiées en utilisant des traceurs de 19 éléments représentatifs différents. Les rendements des éléments contaminants sont réduits dans la plupart des cas à moins de $0.1 \%$, cependant que les rendements d'indium sont d'habitude supérieurs à $95 \%$. La méthode ne nécessite pas d'équipement spécial et prend environ 11 minutes en tout. Un certain nombre de facteurs ayant une action sur la séparatio.s ont été étudiés.

\section{REFERENCES}

1 J. R. DeVoe, C. K. Kim and W. W. Meinke, Talanta, 1960, 3, 298.

2 J. R. DeVoe and W. W. Meinke, Analyt. Chem., 1959, 31, 1428.

8 J. R. DeVoe, H. W. Nass, and W. W. Meinke, ibid., 1961, 33, 1713.

4 W. Latimer, The Oxidation States of the Elements and Their Potentials in Aqueous Solutions. PrenticeHall, Inc., New York, N.Y., 2nd edition, 1952.

${ }^{5}$ W. B. Silker, Analyt. Chem., 1961, 33, 233.

D. N. Sunderman, I. B. Ackermann and W. W. Meinke, ibid., 1959, 31, 40.

'D. N. Sunderman and W. W. Meinke, ibid., 1957, 29, 1578.

${ }^{8}$ D. N. Sunderman and C. W. Townley, Nuclear Science Series Report NAS-NS-3014, The Radiochemistry of Indium, Office of Technical Services, Department of Commerce, Washington 25, D.C., May 1960. 